\title{
As chagas que nos acompanham são as mesmas que nos curam?
}

\author{
The wounds that accompany us are the same ones that heal us?
}

\section{Luis Thiago Freire Dantas*}

Resumo: Este texto interroga acerca do nosso modo de vida a partir da pandemia do SarsCov-2 com o intuito de refletir sobre como interagimos com os outros humanos e nãohumanos. Para isso temos como referência Obaluayê, o Orixá da cura, em diálogo com alguns pensadores que problematizaram a vivência humana nesse atual período. Portanto é um texto propositivo com base na interrogação se as chagas que nos acompanham propiciam outras experiências no mundo?

Palavras-chave: Pandemia; Obaluayê; Filosofia Africana; Covid-19

Abstract: This text questions our way of life from the Sars-Cov-2 pandemic in order to reflect on how we interact with other humans and non-humans. For this we have as reference Obaluayê, the Orixá of cure and disease, in dialogue with some thinkers who problematized the human experience in this current period. Therefore, it is a propositional text based on the question whether the wounds that accompany us provide other experiences in the world?

Keywords: Pandemic; Obaluaye; African Philosophy; Covid-19

"Quem nós cultuamos está junto, ele é aquele que vive na Terra. É para quem nós dançamos, ele está junto de nós”

Iniciar o ensaio com esse canto de louvação (oriki) é firmar um ponto de referência, um guia para a presente escrita. Esse guia é o Orixá Obaluayê com quem estabeleço um diálogo, junto com pensadores indígenas, africanos e asiáticos para pensar o nosso contexto marcado pela expansão global da Covid-19.

Uma doença propagada pelo coronavírus Sars-Cov-2, que modifica a compreensão habitual de fronteira e inaugura outra compreensão espaço-temporal no século XXI, que outrora foi um século idealizado enquanto repleto de tecnologias avançadas, viagens extraterrenas e avanços humanos perante a mobilidade do próprio corpo através da junção com a máquina. Porém, o ano de 2020 marca esse século como aquele que um vírus por meio do rápido contágio pode causar o fim à humanidade, tal como um alerta o próprio planeta já que "O vírus não mata pássaros, ursos, nenhum outro ser, apenas humanos. Quem está em pânico são os povos humanos e seu mundo artificial, seu modo de funcionamento que entrou em crise" 2 .

Essa situação nos remonta a Obaluayê, pois Ele é o Orixá da Terra, que, com o corpo repleto de chagas, cobre-se com palhas, e com o seu xaxará (um cetro ornado com búzios, fios de conta e palhas da costa) domina e espanta as doenças e as epidemias. Com esse

${ }^{1}$ Canto de louvor de Obaluayê retirado do site Toluaye Lokanfu. Disponível em: https://toluaye.wordpress.com/2008/01/25/oriki-obaluaye/ Acesso em 28/04/2020.

${ }^{2}$ KRENAK, $O$ amanhã não está à venda, p. 5. 
domínio Obaluayê tem a capacidade dual de emanar ou curar enfermidades, e também expõe a organização de uma sociedade, pois a maneira como ela lida com a doença reflete o seu envolvimento com o mundo. Um envolver que precisa ser cuidadoso e agradecido, já que "Em sua pequena cabaça traz remédios para livrar-nos das doenças"3. Talvez uma forma para esse cuidado e agradecimento é observar as chagas da sociedade expostas durante essa pandemia para enfim captarmos possíveis mudanças.

Como se sabe, o primeiro epicentro da Covid-19 foi registrado na cidade de Wuhan, na China. Com essa primeira aparição intensificou-se a biovigilância estatal ${ }^{4}$ em vários países asiáticos, biovigilância essa que já era evidenciada em um processo de higienização ${ }^{5}$ e, com a manifestação da doença em outras localidades do planeta a produção de uma linguagem de guerra tornou-se o "comum", que administra quase militarmente até mesmo a respiração ${ }^{6}$. Uma administração que possui a finalidade de gerar a economia financeira e desconfia que a epidemia seja apenas um mero obstáculo ao modo de vida capital. Além disso, não há um questionamento se o modelo de humanidade que hoje perdura possui sobrevida duradoura7. Porém, apesar de tais chagas expostas, visualiza-se um horizonte de libertação através da dança de Obaluayê que firma como sermos humanos no mundo.

\section{Guerrear com o invisível}

A epidemia do Covid-19 acentua as formas que cada país articula-se para impedir a expansão do vírus. Em Wuhan as ações de controle dos corpos intensificaram-se de tal maneira que o Estado gerencia os modos de vida cidadã através de "[...] milhares de equipes de pesquisa digitais que procuram possíveis infectados baseando-se somente em dados técnicos" 8 . Uma das consequências diz respeito ao significado de soberania, pois, conforme destaca Byung Chun Han", o soberano passa a ser aquele que dispõe de dados para averiguar "os que são potenciais infectados, os que precisam continuar sendo observados e eventualmente isolados em quarentena”.

Tal modificação urge justamente pelo inimigo ser invisível a olho nu e, como tal, exige outro maquinário de guerra e, por efeito, o soberano constrói uma série de narrativa para justificar o uso de tal maquinário. Internamente na Ásia, devido à ocorrência de outras crises epidemiológicas $^{10}$, a justificativa deu-se pelo aumento da ética higiênica simbolizada no habitual uso de máscaras que diminuem o contato com o vírus para até mesmo a população civil concordar com a monitoração por meio de aplicativos que indicam em qual local a pessoa de encontra e se há ou não uma aglomeração de pessoas. Byung Hun Chang alerta que essa ação de o Estado saber a localização, as atitudes, os desejos de compra e consumo, bem como de locomoção fundamenta a possibilidade futura para que o "Estado controle também a temperatura corporal, o peso, o nível de açúcar no sangue etc. Uma biopolítica digital que acompanha a psicopolítica digital que controla ativamente as

\footnotetext{
${ }^{3}$ Canto de louvor de Obaluayê retirado do site Toluaye Lokanfu. Disponível em: https://toluaye.wordpress.com/2008/o1/25/oriki-obaluaye/ Acesso em 28/04/2020.

${ }^{4}$ HAN, $O$ coronavírus de hoje e o amanhã

${ }^{5}$ COLETIVO CHUAN. Contágio social: corona vírus, China, capitalismo tardio e o "mundo natural"

${ }^{6} \mathrm{MBEMBE}, \mathrm{O}$ direito universal à respiração

${ }^{7} \mathrm{KRENAK,} \mathrm{O}$ amanhã não está à venda

8 HAN, O coronavírus de hoje e o amanhã

9 Idem

${ }^{10}$ Epidemias como a $\mathrm{H}_{1} \mathrm{~N} 1$, o Sars-Cov em 2003, a gripe suína e a gripe aviária.
} 
pessoas" ${ }^{11}$. Uma situação cada vez mais irremediável de acontecer, precisamente pela crença da necessidade compulsória de higienização dos corpos.

Externamente à Ásia, a narrativa deu-se de outra maneira, primeiro pela incapacidade de gerência na Europa durante a crise epidemiológica concentrada no fechamento de fronteiras, como se o hospedeiro do vírus viesse sempre de fora, o estranho àquele lugar. No entanto, como ressalta o Coletivo Chuan, a epidemia da Covid-19 tem seus impactos beneficiados pela globalização, que incentiva uma agricultura em grande escala e uma urbanização capitalista acentuando a transferência epidemiológica entre animais e humanos. Com isso, as cepas virais passam a ter uma enorme virulência e, no caso da pandemia atual, há a dissolução da existência de uma área mais "selvagem" para a predominância do vírus:

O coronavírus mais recente, em suas origens 'selvagens' e sua súbita disseminação por um núcleo fortemente industrializado e urbanizado da economia global, representa as duas dimensões da nossa nova era de pragas político-econômicas ${ }^{12}$.

Essa condição faz com que os epicentros do vírus mudem geograficamente de maneira acelerada, passando pela Itália, Espanha, Inglaterra e Estados Unidos ${ }^{13}$. Tais locomoções incitam uma previsão e outra forma de lidar com a pandemia. Nesse ponto que dialogar com Obaluayê possibilita uma percepção ampla de tal fenômeno. Uns diálogos feitos através dos Itans, que são relatos sobre histórias dos Orixás e, por causa da oralidade, possuem um caráter interpretativo como também podem receber variações a cada vez que são relatados. Um dos itans de Obaluayê escolhidos para esse ensaio é "Omulu cura todos da peste e é chamado Obaluayê". Com tal título percebemos que se trata de uma transformação do jovem Orixá Omulu que recebe o nome Obaluayê quando adquire o domínio de "cura". E, porventura, essa transformação nos ensina outro modo de lidar com o mundo.

\section{A grande-união: natureza e cultura}

As variações dos Itans se concentram em uma parte que tem como pano de fundo um ensinamento, uma aprendizagem para quem os ouve e também para quem conta. Por exemplo, o surgimento das chagas em Obaluayê possui variações: em um Itan relata que elas surgiram desde o nascimento, como fruto de um relacionamento proibido; já no Itan escolhido para este ensaio a chaga tem explicação a partir das decisões que tomamos. Principalmente por tratar de como o jovem Omulu tornou-se Obaluayê, assim começa o itan:

Quando Omulu era um menino de uns doze anos, saiu de casa e foi para o mundo para fazer a vida. De cidade em cidade, de vila em vila, ia oferecendo seus serviços, procurando emprego. Mas Omulu não conseguia nada.

Ninguém lhe dava o que fazer, ninguém o empregava. E ele teve que pedir esmola mas ao menino ninguém dava nada, nem do que comer, nem do que beber. Tìnha um cachorro que o acompanhava e só.

\footnotetext{
${ }^{11}$ HAN, O coronavírus de hoje e o amanhã

${ }^{12}$ COLETIVO CHUAN. Contágio social: corona vírus, China, capitalismo tardio e o "mundo natural", p. 6

${ }^{13}$ Há uma previsão que o epicentro da pandemia passe a ser o Brasil. Disponível em: https://www.msn.com/pt$\mathrm{br} /$ saude/medicina/o-brasil-vai-virar-o-novo-epicentro-da-pandemia-de-coronav\% $\mathrm{C}_{3} \% \mathrm{ADrus} / \mathrm{ar}-\mathrm{BB} 136 \mathrm{aOI}$

Acesso em 27/04/2020.
} 
Omulu e seu cachorro retiraram-se no mato e foram viver com as cobras. Omulu comia o que a mata dava: frutas folhas, raízes. Mas os espinhos da floresta feriam o menino. As picadas de mosquito cobriam-lhe o corpo. Omulu ficou coberto de chagas. Só o cachorro confortava Omulu, lambendo-lhe as feridas ${ }^{14}$.

Os espinhos, as picadas de mosquito são aquilo que marcam as chagas do corpo menino Omulu. Com a origem no caminhar da vida, diante das escolhas feitas por uma pessoa, desprotegido, ele encontra os infortúnios e apenas é confortado por aquele que compartilha o abandono. Humano e animal se encontram na situação limite do desamparo. Para Achille Mbembe, tal situação revela encontros e exposição a cada todo tipo de risco. Um risco que, como acontece com o coronavírus desde a sua primeira forma, implica a "política do vivo como um todo"15. Uma dimensão política que detém sentido através de vítimas de HIV, malária, zica, chikungunya "e todas as epidemias imagináveis e inimagináveis que devastaram, durante séculos, povos sem nome em terras distantes”.

No entanto, na peregrinação Omulu as chagas já marcavam o seu corpo daquela pela ausência de qualquer ajuda, financeira, alimentícia ou moradia. O menino depara-se com a solidão. Uma solidão característica da vida contemporânea inscrita seja nas crianças debaixo das marquises, nos idosos esquecidos em lares, nos corpos negros à deriva no mar Mediterrâneo ou nos campos de refugiados na Europa e nos EUA. Por isso, o isolamento social alternativa por enquanto mais salutar para evitar a expansão dos vírus incomoda grande parte da população, pois expõe uma situação que não deseja lembrar-se. Com isso, vale enfatizar que "antes deste vírus, a humanidade já estava ameaçada de asfixia"17 e o impacto biológico da covid-19 apenas intensifica e retrata como a capitalização da saúde separa aqueles capazes de adquirir respiradores daqueles que lutam para ter tal capacidade. Não gratuitamente, Mbembe alerta como esses ataques feitos pela Covid-19 aos pulmões humanos é um forma de entendermos "a respiração, para lá de aspectos puramente biológicos, como aquilo que nos é comum e que, por definição, escapa a qualquer cálculo"18. Ou seja, "Falamos, assim, de um direito universal de respiração"19.

E com a sociedade retirando qualquer amparo, Omulu segue para a floresta quase como uma alegoria do retorno à natureza com a intenção de resgatar aquilo que ficou esquecido. Porém similarmente ao que acontece no Itan é justamente quando a cultura deixa de nos tocar que esse retorno aparece como alternativa. Para Omulu, o retorno não foi por uma vontade própria, mas pelo afastamento que a sociedade lhe impôs. E quanto tempo ainda nós temos para encontrarmos alternativas? Porventura, seja um momento em que a Terra esteja nos alertando para uma delas: privilegiar uma vida respirável a todos. Tanto mais, o impacto da Covid-19 nos alerta para "recuperar os recursos do nosso mundo com o fim de forjar novas terras. A humanidade e a biosfera estão ligadas. Uma não tem futuro sem a outra" ${ }^{20}$, ou melhor, a cultura e a natureza possuem uma conexão que não podem ser divididas. Para Omulu o momento em que a compreensão dessa união acontece é através do anúncio de Olorum - aquele que criou todas as coisas:

\footnotetext{
${ }^{14}$ PIERSON, Brancos e pretos na Bahia: estudo de contrato racial, p. 333.

${ }^{15}$ MEMBE, O direito universal à respiração, p. 3 .

${ }^{16}$ Ibid, p. 4.

${ }^{17}$ Idem, ibidem

${ }^{18}$ MBEMBE, $O$ direito universal à respiração, p. 4.

${ }^{19}$ Idem, ibidem

${ }^{20}$ Idem, ibidem
} 
Um dia, quando dormia, Omulu escutou uma voz: 'Estás pronto. Levanta e vai cuidar do povo'. Omulu viu que todas as feridas estavam cicatrizadas. Não tinha dores nem febre. Obaluayê juntou as cabacinhas, os atós, onde guardava água e remédios que aprendera usar com a floresta, agradeceu a Olorum e partiur

Com a presença desse anúncio, outro elemento participa dessa junção entre natureza e cultura: o extramundano. A partir da tríade - humano, animal e espírito - que o menino Omulu tem as feridas cicatrizadas e pode voltar para a sociedade. Contudo sem esquecer a natureza, pois foi nela que aprendeu a respirar.

\section{O silêncio da humanidade}

Atôtô! Silêncio! É a saudação à Omulu/Obaluayê enfatizando que com a chegada do senhor da Terra, o respeito deve permanecer durante a sua passagem. Ailton Krenak ${ }^{22}$ comenta que a própria Terra além de oferecer dádivas ao ser humano, como oxigênio, pássaros a cantar, as correntezas dos rios, Ela pede agora para aprendermos a ficar em silêncio. Inclusive porque o ser humano perpassava a vida com os afazeres em prol do acúmulo, o barulho das máquinas cobrindo todo o resto do planeta e com a expectativa de que o amanhã pudesse render mais. Para isso é necessário fazer uma planilha de tudo adquirido até então, para aperfeiçoar ao máximo antigas ferramentas para adquirir maior rendimento. Ignorando o fato de que "Não sabemos se estaremos vivos amanhã" 33 e, por conseguinte, "Temos de parar de vender o amanhã" 24.

Tal advertência é difícil de escutar, "porque é [o capital] quem faz o mundo dar os seus giros" 25 e, rapidamente, o povo da mercadoria ${ }^{26}$ coloca a maquinaria em movimento. Um movimento justificado pela expressão "a economia não pode parar", no entanto, como Krenak enfatiza: "Se os humanos estão em risco, qualquer atividade humana deixa de ter importância. Dizer que a economia é mais importante é como dizer que o navio importa mais que a tripulação" 27 . Por isso esse confinamento nos exige o silêncio de respeito e de aprendizagem. Ambos estão presentes desde a partida de Omulu da mata em que "Naquele tempo uma peste infestava a Terra":

Naquele tempo uma peste infestava a Terra. Por todo lado estava morrendo gente. Todas as aldeias enterravam os seus mortos. Os pais de Omulu foram ao babalaô e ele disse que Omulu estava vivo e que ele traria a cura para a peste. Todo lugar aonde chegava, a fama precedia Omulu. Todos o esperavam com festa, pois ele curava. Os que antes lhe negaram até mesmo água de beber agora implorar por sua cura. Ele curava todos, afastava a peste. Então dizia que se protegessem, levando na mão uma folha de dracena, o peregum, e pintando a cabeça com efum, ossum e uági, os pós: branco, vermelho e azul, usados nos rituais e encantamentos. Omulu curava os doentes e com o xaxará varria a peste para fora da casa para que a praga não

\footnotetext{
${ }^{21}$ PIERSON, Brancos e pretos na Bahia: estudo de contrato racial, p. 334.

${ }^{22}$ KRENAK, $O$ amanhã não está à venda, pp. 6-7.

${ }^{23}$ KRENAK, $O$ amanhã não está à venda, p. 8.

${ }^{24}$ Idem, ibidem

${ }^{25}$ Edgar. Print

${ }^{26}$ Expressão que Davi Kopenawa utiliza para definir os brancos. Ver o capítulo "Paixão pela mercadoria” em Queda do Céu: palavras de um xamã yanomami, pp. 406-420.

${ }^{27}$ KRENAK, O amanhã não está à venda, p. 7.
} 
pegasse outras pessoas da família. Limpava casas e aldeias com a mágica vassoura de fibras de coqueiro seu instrumento de cura, seu símbolo, seu cetro, o xaxará ${ }^{28}$.

A passagem de Omulu agora trazia festa; aqueles que o menosprezaram lhe pediam a cura. Omulu, passando em cada lugar, ensinava como o caráter ritualístico circunda o ser humano, as interferências além do visível permanecem atuantes mesmo que haja menosprezo ou negação, ainda assim a vida humana é ritualística. Atualmente preocupamos em desinfetar as roupas, alimentos e utensílios por causa do coronavírus, mas mesmo anteriormente seguimos uma série de etapas para alcançar um desejo, ou obter um resultado esperado. Isso é um rito. Mas, a pergunta a ser pensada é: qual foi nossa intenção quando executamos uma ritualística naquele objeto? Nas sociedades subsaarianas de África há uma compreensão de que cada coisa humana, animal, vegetal, mineral, possui uma força que se comunica e se equilibra em um todo vivente. Por isso, não basta festejar a passagem de Omulu "varrendo a peste para fora de casa", mas precisamos rever nosso modo de lidar com o mundo.

Com isso, retomando $\operatorname{Krenak}^{29}$, vale a advertência: "Tomara que não voltemos à normalidade, pois, se voltarmos, é porque não valeu nada a morte de milhares de pessoas no mundo inteiro". Retomar as situações de trabalho confinadas em uma luta pelo oxigênio, distanciar dos laços familiares por causa de aparelhos eletrônicos, ligar todas as máquinas ao mesmo tempo, seria o mesmo que reproduzir o negacionismo: "Aí, sim, teremos provado que a humanidade é uma mentira"30. Para isso, precisamos perceber quais chagas nos cobrem.

\section{Libertar-se das chagas}

Neste ensaio acompanhamos o Itan que relata como Omulu, um menino de doze anos que sai pelo mundo, mas sem qualquer ajuda pela sociedade passa a viver na mata, onde é coberto por chagas. Num certo momento tem suas chagas curadas e cura a todos assolados pela a peste. Ao fim, Omulu retorna para casa, recebido com festas pelo pai e pela mãe, ganha um novo nome: Obaluayê:

Quando chegou em casa, Omulu curou os pais e todos estavam felizes. Todos cantavam e louvavam o curandeiro e todos o chamaram de Obaluaê, todos davam vivas ao Senhor da Terra, Obaluayê ${ }^{31}$.

Como lemos a partir desse Itan, os relatos sobre os Orixás tendem a aproximá-Los do nosso cotidiano e, nesse em específico, destaca que nossa peregrinação pela vida consiste em uma autodescoberta e passa por aquilo que foi recebido pelos outros. Uma peregrinação repleta de chagas que nos define como tal e, por isso mesmo, é capaz de encontrar saídas. Com a Covid-19 rapidamente criou-se uma linguagem de guerra para combater um microorganismo, mas para isso alguns hospedeiros devem perecer e, como na guerra, alguns se sacrificam pelos sobreviventes. Contra tal linguagem, é crucial encontrarmos um caminho que a ressignifique para perceber a Covid-19 como o fenômeno que provoca o descarte de

\footnotetext{
${ }^{28}$ PIERSON, Brancos e pretos na Bahia: estudo de contrato racial, p. 334.

29 KRENAK, O amanhã não está à venda, p. 9.

${ }^{30}$ Idem, ibidem

31PIERSON, Brancos e pretos na Bahia: estudo de contrato racial, p. 334.
} 
vidas humanas, mas tal descarte é consequência de um acúmulo proveniente de uma vivência entre aqueles do puro excesso dos outros que vivem na falta.

Principalmente, com a ausência de vacina ou de remédios que barrem o avanço do vírus, o distanciamento social é o melhor meio para prevenir das possíveis "ondas virais, e paradoxalmente diante dessa conjuntura compreendamos a reconciliação com o outro e com os demais seres vivos enquanto potência de vida. Acontecendo isso, podemos responder positivamente à pergunta de $\mathrm{Mbembe}^{32}$ se "Seremos capazes de redescobrir a nossa pertença à mesma espécie e o nosso inquebrável vínculo à totalidade do vivo?”, e portanto, perceber quais as chagas existentes em nós que podem nos ajudar na cura?

\section{Referências}

COLETIVO CHUAN. Contágio Social: coronavírus, China, capitalismo tardio e o "mundo natural". Pandemia crítica. São Paulo: N-1 edições, 2020. Disponível em https://n-1edicoes.org/022 Acesso em 27/04/2020.

EDGARD. Print. Ultrassom. 6 de setembro de 2018. São Paulo: DeckDisc.

HAN, Byung Chan. O coronavírus de hoje e o mundo de amanhã. El país Brasil. 22 de março de 2020. Disponível em: https://brasil.elpais.com/ideas/2020-03-22/ocoronavirus-de-hoje-e-o-mundo-de-amanha-segundo-o-filosofo-byung-chul-han.html Acesso em 27/04/2020.

KOPENAWA, David; ALBERT, Bruce. Queda do Céu: palavras de um xamã yanomami. São Paulo: Companhia das Letras, 2015.

KRENAK, Ailton. O amanhã não está à venda. São Paulo: Companhia das Letras, 2020.

MBEMBE, Achille. O direito universal à respiração. Tradução de Ana Luiza Braga. Pandemia crítica. São Paulo: N-1 edições, 2020. Disponível em: https://n1edicoes.org/020 acesso em 27/04/2020.

PIERSON, Donald. Brancos e pretos na Bahia: estudo de contrato racial. São Paulo: Nacional, 1971.

OLIVEIRA, Altair Bento de. Cantando para os Orixás. Rio de Janeiro: Pallas, 1997.

${ }^{32}$ MBEMBE, $O$ direito universal à respiração, p. 9. 